\title{
COGNITIVE SCIENCE: FROM MULTIDISCIPLINARITY TO INTERDISCIPLINARITY
}

Dr. Marina Bogdanova, Southern Federal University, Rostov on Don, Russian Federation

E-mail: maraleks27@mail.ru

A R T I C L E I N F O

Studies and Articles

Received: August, 21.2017.

Revised: October, 10.2017.

Accepted: November, 13.2017.

doi:10.5937/IJCRSEE1702145B

UDK

159.922 .72

001.891:159.922.72

\section{Keywords:}

cognitive science, multidisciplinarity, interdisciplinarity,

Paul Thagard,

the metaphor of "trading zone".

\begin{abstract}
A B S T R A C T
Cognitive science is a network of interrelated scientific disciplines engaged in researching human cognition and its brain mechanisms. The birth of cognitive science has been the result of numerous integrated processes. Cognitive science is made up of experimental psychology cognition, philosophy consciousness, neuroscience, cognitive anthropology, linguistics, computer science and artificial intelligence. In recent years, a number of other research areas have been added to the body of cognitive science. Among researchers there have been discussions about whether cognitive science is a separate research area or it consists of a series of specialized areas. In fact, the point at issue is whether cognitive science is still a multidisciplinary project or already an interdisciplinary one. $P$. Thagard believes that cognitive science has reached the level of interdisciplinarity and explains the advances in this area through the metaphor of "trading zones". The success elements of cognitive science are: fruitful unification of scientific interests of cognitive science founders; organizational structure of the scientific community - universities, where a special interdisciplinary intellectual environment has been created; a large number of joint research projects supported by governments and business; integrated use of scientific methods and fundamental ideas. D. Sperber and J. Miller prefer to talk not about a unified cognitive science but cognitive sciences, i.e., the commonwealth of sciences working together on the study of a single object - human cognition, however, the extent of their interactive communication is still small. Thus, we should speak about multidisciplinarity rather than genuine interdisciplinarity of the joint research of separate sciences.
\end{abstract}

(C) 2017 IJCRSEE. All rights reserved.

\section{INTRODUCTION}

Cognitive science is a network of interrelated scientific disciplines engaged in research on human cognition and its brain mechanisms. The subject of cognitive science is various aspects of human cognition and thinking, which, because of its complexity and multidimensional scope, cannot be studied within a single discipline: the laws of perception, mechanisms of processing, storage and reproduction of information, their connection with the human brain and the possibility of realizing information processing in other media;

Corresponding Author

Dr. Marina Bogdanova, Southern Federal University, Russia Federation

E-mail: maraleks27@mail.ru

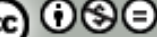

This work is licensed under a Creative Commons Attribution - NonCommercial - NoDerivs 4.0. The article is published with Open Access at www.ijcrsee.com research in the field of artificial intelligence, the role of language in cognition, problems of understanding and interpreting different kinds of texts, the role of evolutionary mechanisms in thinking, the specificity of particular types and styles of thinking.

Questions of cognitive science are themes of the conceptual organizations of human thinking. Do all members of humanity share the same conceptual systems? Is their age, abilities, experience, language, national culture and environment different? The achievements of the sciences dealing with cognition and thinking show the existence of different points of view on these issues and, accordingly, necessitate a comprehensive study of the phenomenon of cognition.

It can be argued that cognitive science has not just become one of the newest trends, but an independent field of theoretical knowledge and practices giving rise to new original ideas and approaches. 


\section{WORLD CENTERS OF COGNITIVE SCIENCE}

Today, a rapidly developing community of cognitive scientists has been working, specialized journals are issued, labs are open and cognitive programs are available in more than 80 universities of the world, most of which are based in American universities (Berkeley, San Diego, Massachusetts, Harvard, Arizona, etc.), but the number of European and Asian programs have also been increasing steadily (Cambridge, Oxford, Tokyo, Singapore, Sofia, etc.).

In Russia, such studies are underway in several centers in Moscow, St. Petersburg and other regions: Kurchatov, the Institute of psychology RAS, Institute of human brain RAS, Institute of Linguistics RAS, Moscow State University named after M. V. Lomonosov, Moscow State Linguistic University, laboratory under the direction of T. V. Chernigovskaya, St. Petersburg State University, Center for cognitive programs and technologies of the RSUH. Among the regional centres Tambov State University named after G. R. Derzhavin should be particularly mentioned, laboratory of cognitive sciences at the Institute of Information technoligies of Kazan state University, cognitive center in Irkutsk, the centers for cognitive studies in Kaliningrad, Yekaterinburg, Pyatigorsk, Voronezh, Barnaul, Tyumen and others.

\section{THE BIRTH AND STAGES OF DEVELOPMENT OF COGNITIVE SCIENCE}

The birth of cognitive science was the result of many interrelated processes: historical, political, economic and scientific itself. Scientific assumptions are considered to be the advances in understanding the nature of cognitive processes: the creation of computational models of mind in mathematical studies (A. Turing, C. Shannon), modelling the mind in the works of neurophysiologists, based on the principles of cognitive processing of information in neural networks (W. McCulloch, W. Pitts, K. Lashley); the achievements of cybernetics, which developed the information theory and the computer model for understanding computing systems (N. Wiener); the development of discursive psychology and narratology (J. Bruner, J. Brockmeier and R. Harre), and others.
Early formation of the cognitive paradigm applies to the 50-60s of the XX century. Some authors even mention the exact date of the emergence of the cognitive sciences - 11 September 1956. On that day Massachusetts institute of technology held a symposium on informatics, which heard three reports defining cognitive science a field of interdisciplinary research: the report on a cell model of human memory by an experimental psychologist G. Miller . The report made by the representatives of the computer science A. A. Newell and $\mathrm{H}$. Simon which was the first to announce the computer metaphor of the brain has become a basic theoretical concept in cognitive sciences. And the report of N. Chomsky, who formulated his research program, which was to explain the human ability to master a language.

G. Miller, noting the epochal events, occurred on this forum, remembers: "I left the symposium with a firm conviction, more intuitive than rational, that experimental human psychology, theoretical linguistics and computer modelling of cognitive processes is part of an even larger whole, and in the future we will see consistent development and coordination of their joint work. I had been heading for cognitive science for twenty years before I learned its name" (Falkman, 2014, p.21).

Cognitive science of the first generation relied on the "computer" metaphor of the mind which meant that the mind was considered in a similar way to computing devices and primarily to a computer. The upmost idea was that human consciousness worked the same way as a computer program. The foundations for the development of computational models of the mind were laid by mathematicians A. Turing, C. Shannon, neurophysiologists W. McCulloch, W. Pitts, and K. Lashley.

The second stage in the development of cognitive sciences began in the 70 s with the work of cognitive psychologists: J. Brunner, U. Neisser, G. Lakoff, M. Johnson, and others. The essence of the "second cognitive revolution" was to return science to a person after "a long cold winter of objectivism" (Bruner, J. S., 1990, p. 1).

In his works G. Lakoff insists on the importance of the bodily organization of a man in the processes of thinking organization. Human thought is determined by the nature of the organism, ensuring its (thought) functioning, and all those factors that contribute to the accumulation, interpretation and relevant experience. Such factors are considered by G. Lakoff as genetic inheritance, the environment 
and the way of his existence in it: "Human reason is not an instantiation of transcendental reason; it grows out of the nature of the organism and all that contributes to its individual and collective experience: its genetic inheritance, the nature of the environment it lives in, the way it functions in that environment, the nature of its social functioning, and the like." (Lakoff, 2008, p. 6).

In cognitive science, the assertion gathering the majority support says that it is impossible to understand the human mind, cognitive functions of the human intellect if the mind is abstracted from the body, its physicality, due to the evolutionary abilities of perceiving the world through sense organs (eyes, ears, nose, tongue, hands), from the organism involved in a certain situation, ecological environment.

Thus, the main vector in the development of cognitive science of the second generation is its turn from the abstract "systems of information processing" back to the person, as a creature endowed with a physical body, emotional and volitional sphere, belonging to the society and interacting with people.

At the present stage of cognitive science development which is called the neural network or connectionism determination of consciousness and cognition is associated with a regulatory part of the culture in the work of consciousness and human cognition. The cognitive system is seen as a triangle with two equal sides whose vertices are the brain, the body and the external environment (culture). A supporter of this approach to understanding consciousness is D. Dennett, characterizing consciousness as a complex phenomenon that cannot be reduced to anatomy or neurophysiology of the brain, but which is formed at the junction created "shimmering" of natural and cultural. "Human consciousness is to a very large extent is a product of not only natural selection but also cultural evolution." (Dennett, D. C., 1991:2, p. 202).

Using the idea of cultural genes, borrowed from books by R. Dawkins "The Selfish Gene", D. Dennett talks about equal determinism of consciousness nature and culture. If the vectors of genes are organisms, the carriers of a cultural code are pictures, books, sayings, various inventions.

\section{NEW PROMISING RESEARCH DIRECTIONS}

Thus, the concept of "cognitive science" is not limited to the study of cognition in the classical epistemological sense. Most of cognitive science studies are applied in nature, there are new promising research directions. For example, among the psychological sciences they are: cognitive psychology of emotions, studying the relationship of cognition and emotion; social cognitive science, which studies all aspects of knowledge of an individual that is part of the community. There are cognitive psychophysiology and cognitive neuroscience.

Recently, there has been a number of new areas, amounting to a substantial body of cognitive science, having access into practice: cognitive aesthetics and neuroaesthetics, cognitive genetics, cognitive poetics, neuroethology, cognitive economics and neuroeconomics. For example, the focus of the study of cognitive neuroeconomics is the problems of the influence of brain processes on consumer behavior. Developments carried out under these research projects can help to answer the questions about how to create conditions for promoting this or that consumer choice, which design to choose for a particular product, etc.

The newest and a very popular area of research - "necromage"- is a research direction at the crossroads the psychology of attention, neuroscience and the practice of professional illusionists. This direction deals with the study of limits and errors of human perception, studying not only circus tricks and activities of professional pickpockets, but also road accidents, wrong medical diagnosis and many other professional and consumer errors. Research programs are also implemented by cognitive jurisprudence, dealing with detecting the interaction between the brain processes and offending behavior.

Finally, "cultural neuroscience" is booming; the area deals with the study of the structural and functional brain plasticity in the development of various forms of cultural practices (for example, literacy, numeracy, occupations, sports, etc.), on the one hand, and the study of brain and genetic correlates of stylistic peculiarities of the knowledge of the representatives of different cultures, on the other hand.

\section{DISCUSSION}

Despite all the achievements of cognitive scientists, among researchers, there have been discussions about whether the cognitive science is a separate research area or consists of a number of specialized areas in which each 
science retains its autonomy. In fact, the matter is whether the cognitive science is a multidisciplinary or already an interdisciplinary one.

Since the 1980s, cognitive science has been considered as the developed interdisciplinary education. However, what is the degree of interdisciplinarity? What are the real relationships between the separate cognitive disciplines and how to compare their contribution to overall cognitive thing? Has the dream of the founders of cognitive science fulfilled concerning its real interdisciplinarity?

In order to understand the severity of the debate unfolded on the status of cognitive science, it is necessary to reveal the essence of the concept «interdisciplinarity» and «multidisciplinary». Interdisciplinarity is used in cases when different disciplines interact with each other to form a new discipline (thus, for example, biochemistry or biophysics were formed), or when theoretal concepts or research technologies of one disciplinary field penetrate into the other, being used there for resolving disciplinary issues.

Multidisciplinary can be considered as a study, when any object (such as thinking) is studied simultaneously from different perspectives by several independent scientific disciplines. Each discipline uses its own methodology, theoretical assumptions, contributes to the "common fund" of knowledge about an object. Interdisciplinarity involves rather cooperation in various areas of knowledge, using general concepts than overall research field.

Paul Thagard, the Director of the program in cognitive science at Waterloo University (Canada), believes that cognitive science has reached the level of interdisciplinarity, and explains the success in this area through the metaphor of "trading zones" borrowed from anthropology. P. Thagard has developed a success formula of cognitive science. Success elements of cognitive science are: the fruitful unification of scientific interests of the founders of cognitive science, who wanted to overcome the barriers of disciplinarity; the organizational structure of the scientific community - universities, with their departments, centers, and programs where special interdisciplinary intellectual environment is created; a large number of joint research projects, supported by the governments and businesses; the integrated use of scientific methods; the fundamental ideas adopted by the representatives of different sciences: the notion of representation, computation and brain-like computing device.
D. Sperber, G. Miller prefer to talk not about a unified cognitive science but cognitive sciences, i.e., the commonwealth of sciences working together to study one object - the human cognition, herewith, the degree of their interaction is still small. On the basis of their research conducted there is a conclusion that the dominant position in the cognitive science is occupied by two out of the six disciplines - psychology and computer science, the others make a very modest contribution to the development of cognitive science as a whole. To make breakthrough achievements possible among other things specialists must have an idea what their team members deal with.

Thus, we should speak more about multidisciplinary nature, than about the true interdisciplinarity of their joint research. D. Sperber, in this regard, proposed the term "cosmetic interdisciplinarity", denoting by this term those projects that are multidisciplinary in nature.

Back in the mid 80-s of the last century H. Gardner wrote: "currently the representatives of the cognitive science come into this area of research from a number of specialized areas, namely: philosophy, psychology, artificial intelligence, linguistics, anthropology, or neuroscience. But I hope that one day the boundaries between these areas would be weakened and can be completely erased, and there will be a single unified cognitive science" (Federova, 2014, p. 28).

And finally, again to demonstrate the difficulty of interdisciplinary cooperation, it should bring the ten stages on the path to scientists' approval by Swedish zoologist D. Solander (Federova, 2014, p. 26-27), who with a humorous undertone talks about this problem. At the first stage, which D. Solander calls "everyone sings the old songs" the representatives of different sciences deal exclusively with their problems, looking down on colleagues from other areas. At the second stage, called "everyone on the other side is an idiot" scientists from different disciplines are beginning to glance at each other, while noticing nothing but flaws and, as a result, many interdisciplinary projects at this stage end. If, nevertheless, future colleagues manage to reach the third stage - "retreating into abstractions", it is easier to agree on abstract issues, but as soon as they move on to specific issues - business comes to a standstill. At the fourth stage - "the definition sickness" they realize the problem of necessity to develop a language for interdisciplinary collaboration, they create a kind of jargon, incomprehensible to others. The fifth 
stage, "jumping into tussocks" is the beginning of fruitful discussions on selected topics, but it is reminiscent of "jumping over bumps" when the overall picture cannot be created. At the sixth stage, called "the glass bead game", the intellectuals come to an agreement through overcoming difficulties and trade-offs. The seventh stage - "the great failure" - a failure, a stage of disappointment, a sense of the futility of further cooperation.

Most projects end at this stage. However, at the eighth stage - "what happens to me?", when it would seem that cooperation has not happened and interdisciplinary project has failed, there comes an understanding that not everything is so bad and pessimistic estimations are exaggerated. At the penultimate ninth stage, which is called "getting to know the enemy", scientists are not only interested in the specific areas of a related science, but show interest in the depth of its spheres: structure, methodology, tasks. The tenth stage - "the real beginning" is the beginning of a real process of interaction among scientists of different disciplines, the beginning of a real interdisciplinary integration.

\section{CONCLUSION}

Thus, having developed in front of us, cognitive science is an isolated situation of interdisciplinary interaction of sciences, within which scientific approaches, theories, models and empirical material freely circulate without strict linking to relevant sectors of a science, whereby it is possible to achieve integrated, holistic knowledge, provide a systematic analysis of problems, an effective way in the practical field and a rich communicative environment for scientists and researchers.

\section{Conflict of interests}

The author declare no conflict of interest.

\section{REFERENCES}

Bruner, J. (1990). Acts of Meaning. Cambridge, MA. Harvard University Press. Developmental Psychology, 13(4), 377-388.

Dennett, D. C. (1991). Consciousness Explained (Boston, Toronto and London: Little, Brown and Company). Dennett, Daniel C.(1994): Philosophie des menschlichen Bewußtseins [übers. v. Franz M. Wuketits].

Falikman, M. (2014). Cognitive science: background and prospects, Journal Logos, 1(97), 1-18.

Fedorova, O. (2014). A and B were sitting on the tube, or Interdisciplinarity of cognitive research, Journal Logos, 1(97), 19-34.
Lakoff, G.(2008). Women, fire, and dangerousthings. University of Chicago press. https://goo.gl/jYnDbZ 